www.jmscr.igmpublication.org

Impact Factor 5.84

Index Copernicus Value: 71.58

ISSN (e)-2347-176x ISSN (p) 2455-0450

crossref DOI: _https://dx.doi.org/10.18535/jmscr/v5i12.38

Journal Of Medical Science And Clinical Research

IGM Publication

An Official Publication of IGM Publication

\title{
Differentiation of Solid Breast Masses into Benign and Malignant by Using Gray Scale Ultrasonography and Strain Elastography
}

\author{
Authors
}

Anjali Pravinkumar Wasadikar', Manoj Baburao Jadhav², Varsha Jagannath RoteKaginalkar $^{3}$, Pravinkumar Prabhakar Wasadikar ${ }^{4}$, Pankaj Satyanarayan Jha ${ }^{5}$

${ }^{1}$ Associate Professor, Department of Radio diagnosis, Government Medical College, Aurangabad,

Maharashtra-431001, India Email: anjalipravinpo@gmail.com

${ }^{2}$ Post-Graduate, Department of Radio diagnoses, Government Medical College, Aurangabad, Maharashtra,

India Email: jadhavmanoj580@gmail.com

${ }^{3}$ Professor and Head, Department of Radio diagnosis, Government Medical College, Aurangabad,

Maharashtra, India Email: Kaginalkar@gmail.com

${ }^{4}$ Associate Professor, Department of General Surgery, Government Medical College, Aurangabad,

Maharashtra, India Email: anjalipravinpo@gmail.com

${ }^{5}$ Post-Graduate, Department of Radio diagnoses, Government Medical College, Aurangabad, Maharashtra, India Email: pankaj.jha201289@gmail.com

Corresponding Author

Dr Anjali Pravinkumar Wasadikar

39, Ulkanagari, Near Omprakash Mandir, Garkheda area, Aurangabad, Maharashtra -431001, India Email: anjalipravinpo@gmail.com Phone: +919767400925

\section{Abstract}

Objectives: The purpose of this study was to evaluate diagnostic performance of grayscale ultrasonography and strain elastography in distinguishing between benign and malignant solid breast masses, with cytological and histopathological results as reference standard.

Materials and Methods: Total 100 solid palpable breast masses in 100 women with mean age 38.95 years were studied using BI-RADS (Breast Imaging Recording and Data System) lexicon and strain ratio (SR) in the same settings and categorized into benign and malignant groups. Comparative analysis of sonographic parameters and strain ratio was done with cytological and histopathological diagnosis. Statistical analysis included sensitivity, specificity, and positive and negative predictive values for both gray scale ultrasonography and strain ratio.

Results: Cytological and histopathological diagnosis revealed 62 benign and 38 malignant lesions. Gray scale ultrasonography had sensitivity of $92.11 \%$, specificity of $83.87 \%$, positive predictive value of $77.78 \%$ and negative predictive value of $94.55 \%$. For strain ratio, the mean \pm standard deviation was6.16 \pm 2.92 for malignant lesions and $2.41 \pm 1.65$ for benign lesions ( $p<0.001$ ). By using best cut-off of 3 between benign and malignant, sensitivity of $89.47 \%$, specificity of $85.48 \%$, positive predictive value of $79.07 \%$, and negative predictive value of $92.98 \%$ obtained for strain ratio.

Conclusion: By combining gray scale ultrasonography and strain elastography the number of false results can be reduced with increase in overall yield of examination and subsequent reduction of unnecessary biopsies.

Keywords: Breast; Gray scale ultrasonography; Strain ratio; Neoplasm. 


\section{Introduction}

Breast cancer is the most frequent cancer in women globally and represents the second leading cause of cancer death among women ${ }^{(1)}$. Increased breast tissue density in younger population decreases diagnostic accuracy of mammographic screening hence other modalities needs to be considered. The inability of ultrasonography to pick up micro calcification has led to its main limitation as a screening procedure. But it plays important role in evaluation of palpable breast masses. In recent years, a variety of manufacturers have begun to incorporate elastography, a realtime tissue stiffness measuring technique in ultrasound equipment. In the breast, cancers tend to be stiffer than benign lesions, and elastography has also been reported to improve the specificity for the diagnosis of solid breast masses ${ }^{(2-4)}$. Several prior clinical studies used various diagnostic criteria's of elastography for better discrimination of breast masses such as discrepancy of size of lesions, 5-point scoring system based on visual assessment of the degree and distribution of strain in the hypo echoic mass and surrounding tissue. However, inter observer variability in data acquisition and interpretation has been shown as a limitation of the use of ultrasound elastography. Hence more quantitative criteria of strain ratio were introduced. At our institute we compared the diagnostic performance of strain elastography (SE) with gray scale ultrasonography (USG) in differentiating solid breast masses into benign and malignant ones.

\section{Material and Methods}

The present prospective study was carried out at our institute between January 2014 and December 2016 which was approved by institutional review board. Written, informed consent was obtained from all enrolled patients. All women presenting with palpable solid breast masses were included in the study. Patients with breast implants, patients undergoing chemotherapy or radiotherapy and those having large fungating breast masses were excluded from study. Breast examination of selected patients was carried out on Aloka Pro Sound Alpha 7 ultrasound machine (Hitachi Medical, Tokyo, Japan) with linear array transducer of 7-12MHz frequency. Total 100 solid breast masses studied in 100 patients, which were referred from surgery department for sonographic evaluation.

\section{Examination Technique}

The detected breast lesions were localized by the clock face method and described according the sonographic BI-RADS lexicon ${ }^{(5)}$ using sonographic descriptors for shape, orientation, margins, echo pattern, posterior acoustic features, and calcification. On the basis of these descriptors, each lesion was assigned a final category. Strain ratio was calculated by changing setting to strain elastography.

\section{Technique of elastography}

After stabilizing the transducer perpendicular to the lesion dual elastographic program was initiated. A slight rhythmic compression decompression movement was applied. The scale for degree of compression was kept between level 3 and 4. The strain ratio (fat to lesion) was calculated by dividing the strain value of normal breast parenchymal fat by that of the breast lesion. Strain ratio of 3.0 was used as cut-off for differentiating between benign and malignant neoplastic lesions. Strain ratio and BI-RADS categories were correlated with cytologic and histopathological diagnosis obtained from fineneedle aspiration biopsy, core needle biopsy, or surgical biopsy, respectively.

\section{Statistical analysis}

A result was categorized as false positive when diagnostic method classified histologically confirmed benign lesion as malignant. A result was categorized as false negative when diagnostic method classified histologically confirmed malignant lesions as benign. When diagnostic method classified lesions in concordance with histopathology results, they were labelled as true positive and true negative. The diagnostic performance of strain elastography and gray scale ultrasonography assessed by calculating 
sensitivity, specificity, positive predictive value (PPV), negative predictive value (NPV). P value < 0.05 was considered as statistically significant. Results of this study were analysed and compared with other available studies in literature

\section{Results}

The mean age of patients with benign neoplastic breast lesions was $31.92 \pm 11.4$ and with malignant neoplastic lesion was $50.42 \pm 12.62$. There was statistically significant difference between mean age of the patients with benign and malignant neoplastic breast lesions ( $\mathrm{P}$ value $<0.001$ ).

\section{Cytohistological diagnosis}

Cytohistological diagnosis revealed 62 benign and 38 malignant lesions. Among the total 38 malignant neoplastic lesions, the most common was infiltrative ductal carcinoma (66\%). Among the benign masses fibro adenoma (77\%) was commonest cytohistological diagnosis. Percentage distribution of benign and malignant neoplastic masses is shown in Table 1.

\section{Gray scale ultrasonography}

Ultrasonographic features with their PPV of benignity and malignancy are shown in Table 2. Gray scale ultrasonography revealed 35 true positives (TP), 52 true negatives (TN), 10 false positives (FP) and 3 false negatives (FN). Gray scale USG had sensitivity of $92.11 \%$, specificity of $83.87 \%$, positive predictive value (PPV) of $77.78 \%$ and negative predictive value (NPV) of $94.55 \%$.

\section{Strain Elastography}

The mean strain ratio in benign neoplastic lesions was $2.41 \pm 1.65$ (range 0.6 to 8 ) and in malignant lesions $6.16 \pm 2.92$ (ranges 2.1 to 15 ). By using cut-off of 3 strain elastography showed 34 true positives (TP), 53 true negatives (TN), 9 false positives (FP) and 4 false negatives (FN). Sensitivity of $89.47 \%$, specificity of $85.48 \%$, positive predictive value of $79.07 \%$ and negative predictive value of $92.98 \%$ was obtained for strain elastography using strain ratio
Table 1. Percentage Distribution of Benign and Malignant Neoplastic Masses

\begin{tabular}{|l|c|c|c|}
\hline Benign Lesions & $\mathbf{N}(\%)$ & $\mathbf{N}(\%)$ \\
\hline Mibro adenoma & $48(77)$ & $\begin{array}{c}\text { Infilignant } \\
\text { Lesions } \\
\text { carcinoma }\end{array}$ & $25(66)$ \\
\hline $\begin{array}{l}\text { Fibro adenoma } \\
\text { with atypia }\end{array}$ & $1(2)$ & $\begin{array}{c}\text { Ductal carcinoma } \\
\text { in situ }\end{array}$ & $5(13)$ \\
\hline $\begin{array}{l}\text { Benign neoplastic } \\
\text { lesion }\end{array}$ & $7(11)$ & $\begin{array}{c}\text { Invasive lobular } \\
\text { carcinoma }\end{array}$ & $2(5)$ \\
\hline $\begin{array}{l}\text { Benign neoplastic } \\
\text { lesion }\end{array}$ & $3(5)$ & $\begin{array}{l}\text { Medullary } \\
\text { carcinoma }\end{array}$ & $2(5)$ \\
\hline $\begin{array}{l}\text { Lipoma } \\
\text { Mucinous } \\
\text { carcinoma }\end{array}$ & $3(8)$ \\
\hline $\begin{array}{l}\text { Intraductal } \\
\text { Papilloma }\end{array}$ & $1(2)$ & $\begin{array}{c}\text { Scirrhous } \\
\text { carcinoma }\end{array}$ & $1(3)$ \\
\hline Total & $62(100)$ & Total & $38(100)$ \\
\hline
\end{tabular}

(N-number, \%-percentage)

Table 2. Gray Scale USG Features with PPV for Malignancy and Benignity

\begin{tabular}{|l|c|c|c|}
\hline $\begin{array}{l}\text { Gray scale sono- } \\
\text { graphic features } \\
\text { with high PPV for } \\
\text { malignancy }\end{array}$ & $\begin{array}{c}\text { PPV } \\
(\%)\end{array}$ & $\begin{array}{c}\text { Gray scale } \\
\text { sonographic } \\
\text { features with high } \\
\text { PPV for benignity }\end{array}$ & $\begin{array}{c}\text { PPV } \\
(\%)\end{array}$ \\
\hline Spiculated margin & 100 & $\begin{array}{c}\text { Well circumscribed } \\
\text { margin }\end{array}$ & 95.55 \\
\hline Micro calcification & 100 & Oval shape & 85.36 \\
\hline Micro lobulations & 75.00 & Macro lobulations & 69.23 \\
\hline Irregular shape & 78.37 & Parallel orientation & 85.10 \\
\hline
\end{tabular}

\section{Discussion}

Over the last decade, there has been increasing interest in imaging the elasticity of biological tissues to complement information from standard anatomical imaging. Elastography can differentiate between benign and malignant lesions on the basis of their firmness. The strain ratio represents the relative compliance and stiffness of lesions compared with surrounding tissues. Malignant lesions, which are very stiff, deform less whereas benign lesions deform much more easily.

Total malignant neoplastic lesions in present study were $38(38.00 \%)$ and benign neoplastic were 62 $(62.00 \%)$. Different previous studies noted significant higher proportion of benign lesions ${ }^{(6,7)}$. The commonest benign lesion was fibro adenoma $(77 \%)$ while infiltrative ductal carcinoma $(66 \%)$ was commonest malignant lesion. Mean age of the patients in present study with malignant neoplastic 
lesions $(50.42 \pm 12.62)$ was significantly higher than benign neoplastic lesions $(31.92 \pm 11.4, \mathrm{P}$ value < 0.001) which were consistent with previous literature ${ }^{(8,9)}$. When we analysed gray scale USG findings, most common characteristic features of malignancy were: spiculated margins, micro calcification, irregular shape, micro lobulations and non-parallel orientation. PPV of various benign and malignant features obtained in present study are compared with previous studies in Table 3 and 4.

PPV of spiculated margins for malignancy in present study is $100 \%$ which is higher than previously reported ${ }^{(10-12)}$. All lesions with spiculated margins turned out as malignant. PPV of irregular shape, non-parallel orientation for malignancy is comparable to that of Hong AS ${ }^{(11)}$. PPV of irregular shape, anti-parallel orientation and decreased sound transmission (shadowing) for malignancy in the study conducted by Melania Costantini $^{(12)}$ are comparable with our study. Soo MS et $\mathrm{al}^{(13)}$ observed suspicious micro calcification on sonography in only $23 \%$ cases but, when detected are malignant and represent invasive cancer. Similarly, we noted eleven cases with micro calcification which were proved to be malignant.

Table 3.Comparison of PPV of Benign Features with Previous Studies

\begin{tabular}{|c|c|c|c|c|}
\hline \multirow[b]{2}{*}{$\begin{array}{l}\underset{\text { Gray study }}{\stackrel{\text { scale }}{\text { feature } \downarrow}}\end{array}$} & \multicolumn{4}{|c|}{$\begin{array}{c}\text { Positive Predictive Value (PPV) for } \\
\text { Benignity }\end{array}$} \\
\hline & $\begin{array}{l}\text { Stavros } \\
\text { AT }^{(10)}\end{array}$ & $\begin{array}{l}\text { Hong } \\
\text { AS }^{(11)}\end{array}$ & $\underset{C^{(12)}}{\text { Melania }}$ & $\begin{array}{l}\text { Present } \\
\text { Study }\end{array}$ \\
\hline Oval Shape & $91.1 \%$ & $84 \%$ & $79.7 \%$ & $85.3 \%$ \\
\hline $\begin{array}{l}\text { Well } \\
\text { Circumscrib } \\
\text { ed Margin }\end{array}$ & - & $90 \%$ & $87.8 \%$ & $95.5 \%$ \\
\hline $\begin{array}{l}\text { Parallel } \\
\text { Orientation }\end{array}$ & - & $78 \%$ & - & $85.1 \%$ \\
\hline
\end{tabular}

Table 4. Comparison of PPV of Malignant Feature with Previous Studies

\begin{tabular}{|c|c|c|c|c|}
\hline \multirow[b]{2}{*}{$\begin{array}{l}\text { Study } \\
\text { Gray scale } \\
\text { feature }\end{array}$} & \multicolumn{4}{|c|}{$\begin{array}{c}\text { Positive Predictive Value (PPV) for } \\
\text { Malignancy }\end{array}$} \\
\hline & $\begin{array}{c}\text { Stavros } \\
\text { AT }^{(10)}\end{array}$ & $\begin{array}{l}\text { Hong } \\
\text { AS }^{(11)}\end{array}$ & $\underset{C^{(12)}}{\text { Melania }}$ & $\begin{array}{c}\text { Present } \\
\text { Study }\end{array}$ \\
\hline Spiculated Margin & $91.8 \%$ & $86 \%$ & $87.5 \%$ & $100 \%$ \\
\hline $\begin{array}{l}\text { Anti-parallel } \\
\text { Orientation }\end{array}$ & $81.2 \%$ & $69 \%$ & $71.3 \%$ & $71.8 \%$ \\
\hline Irregular Shape & - & $62 \%$ & $62 \%$ & $78.37 \%$ \\
\hline $\begin{array}{l}\text { Posterior Acoustic } \\
\text { Shadowing }\end{array}$ & $65 \%$ & - & $78.9 \%$ & $67.5 \%$ \\
\hline Microlobulation & - & - & $100 \%$ & $75 \%$ \\
\hline
\end{tabular}

Features with high PPV of benignity were well circumscribed margins, oval shape, macro lobulations and parallel orientation. These observations are in accordance with previous studies $^{(10,11)}$. Sensitivity, specificity, PPV and NPV of gray scale USG in present study is

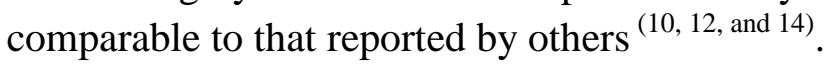

A mean strain ratio of benign lesions is significantly lower than malignant lesions $(2.41 \pm 1.65$ Vs 6.16 \pm 2.92 : $\mathrm{p}<0.001)$. Figure 1 and 2 are representative cases of benign and malignant lesions respectively in which gray scale USG diagnosis and strain elastography diagnosis is consistent with histopathology result. Those low strain ratios for benign masses correspond with values reported in the literature ${ }^{(15-17)}$. We noted high strain ratio (11.33) in scirrhous carcinoma which could be attributed to its high fibrous content. There is overlap of the elasticity between benign and malignant lesions in the breast ${ }^{(18)}$.

Two cases of fibro adenomas with internal calcification and one with atypia showed high strain ratio on elastography and were misdiagnosed as malignant. Figure 3 is example of one of the fibro adenoma with internal calcification. But on gray scale ultrasonography they were correctly categorized as benign. In remaining six false positive cases, we could not find any specific histological features to explain high strain ratio. This may be due to technical error as this technique is operator dependent. 


\section{JMSCR Vol||05||Issue||12||Page 31456-31463||December}

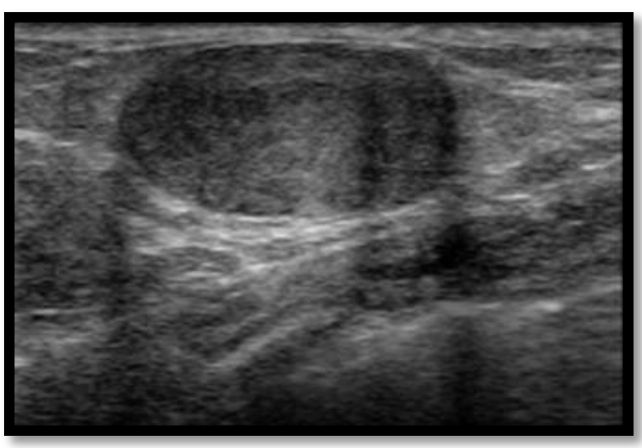

A.

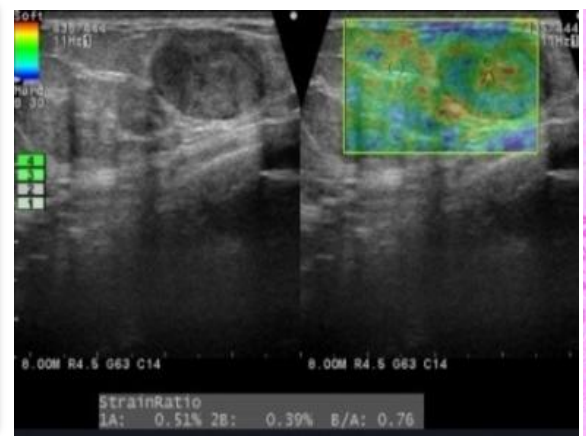

B.

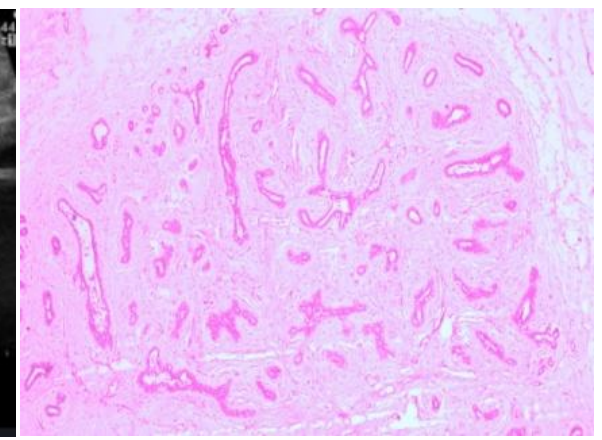

C.

Figure 1. 45-year-old woman with palpable lump in left breast A. Gray scale ultrasound shows a well circumscribed 17x10mm sized hypo echoic oval lesion which was categorized as -BI-RADS - 2. B. Strain elastography image reveals homogeneous green soft lesion with strain ratio 0.76 calculated as fat strain (B$0.39 \%$ ) divided by lesion strain (A-0.51\%).C. Histopathological result -Fibroadenoma

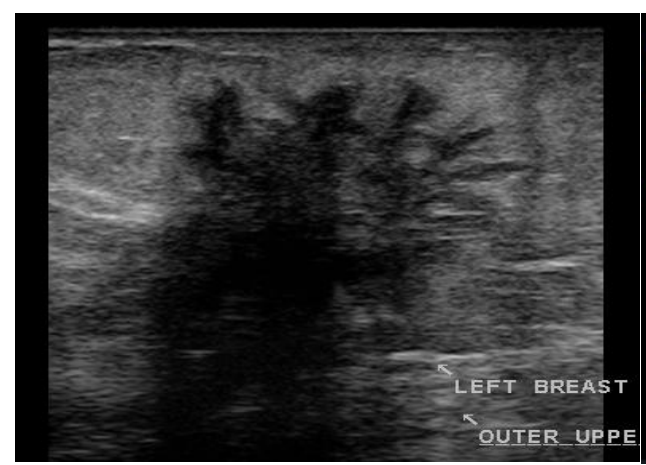

A.

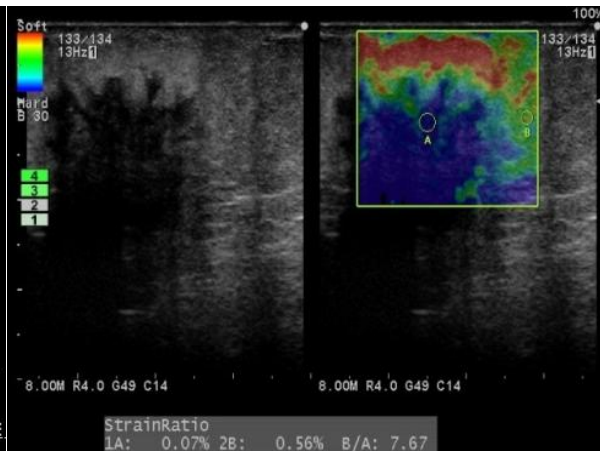

B.

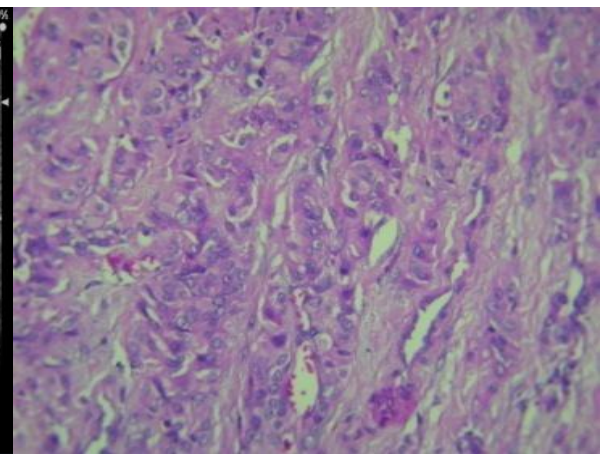

C.

Figure 2. 65 year female presented with painless hard lump in left breast A. Gray scale image shows an irregular 23x21mm sized an irregular spiculated hypo echoic lesion with posterior shadowing -BI-RADS -5. B. Strain elastography image reveals blue hard lesion with strain ratio 7.67 calculated as fat strain (B- $0.56 \%)$ divided by lesion strain (A-0.07\%).C. Histopathological result - Infiltrative ductalcarcinoma

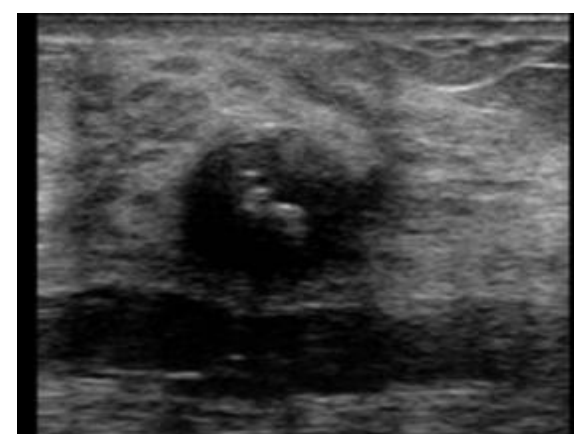

A.

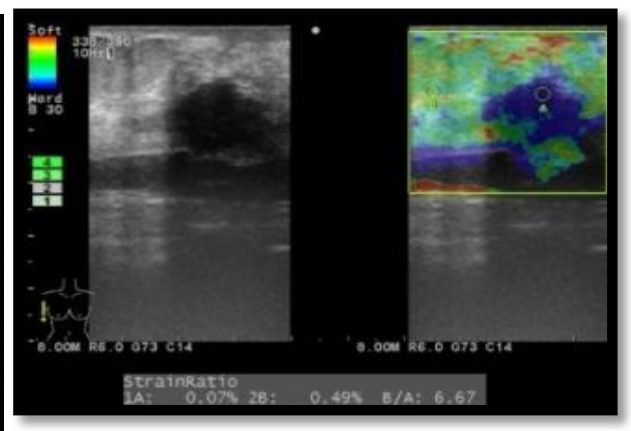

B.

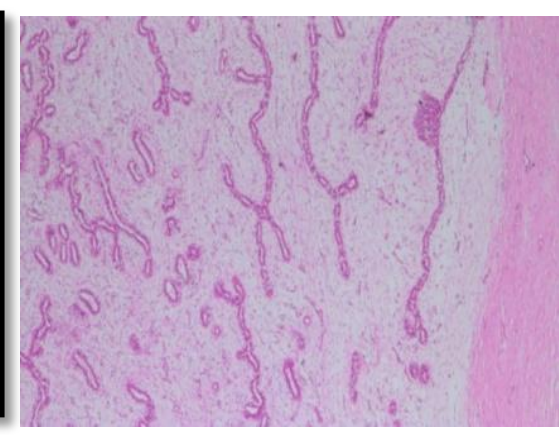

C.

Figure 3. 50-year-old woman with palpable lump in right breast A. Gray scale ultrasound shows a well circumscribed 17x18 mm sized hypo echoic rounded lesion with internal macro calcification and posterior shadowing was categorized as -BI-RADS -3. B. Strain elastography image reveals blue hard lesion with strain ratio 6.67 calculated as fat strain (B-0.49\%) divided by lesion strain (A-0.07\%).C .Histopathological result showed -Fibroadenoma 


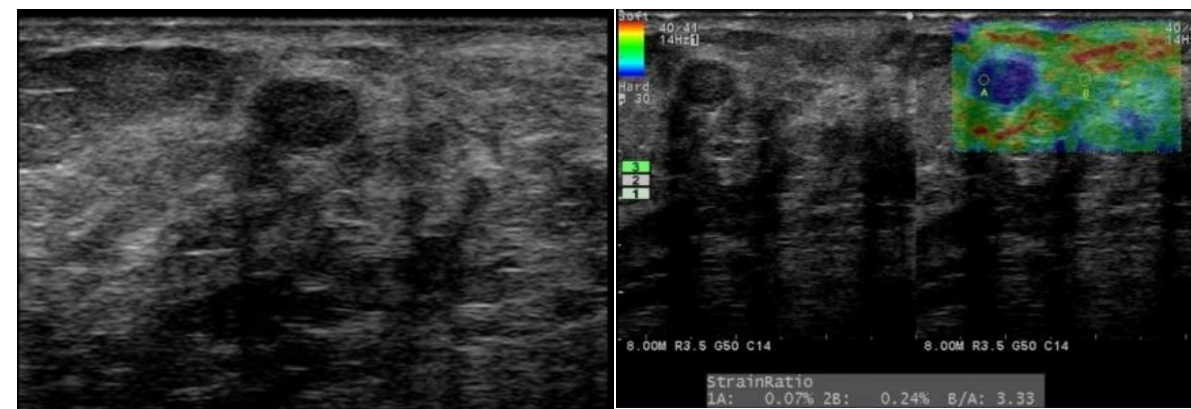

A.

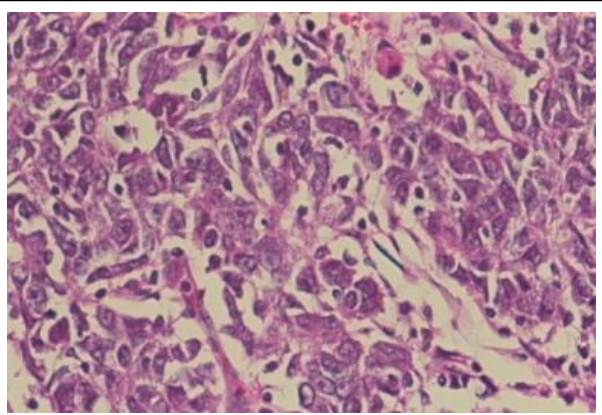

C.

Figure 4. 39 year female palpable lump in right breast A. Gray scale image shows an a well circumscribed hypo echoic rounded lesion of size 16x13 mm-BI-RADS-2. B. Strain elastography image showed strain ratio 3.33 calculated as fat strain (B-0.24\%) divided by lesion strain (A-0.07\%).C .Histopathological result Medullary carcinoma

In two cases of medullary carcinoma gray scale findings were suggestive of benign features of the lesions however strain elastography revealed high strain ratio suggesting malignant aetiology. Figure 4 shows example of a medullary carcinoma misdiagnosed as benign lesion on gray scale sonography which was correctly diagnosed as malignant lesion by strain elastography. Lower strain ratios were observed in four malignant lesions: each of two infiltrative ductal carcinoma and mucinous carcinoma. Soft nature of mucinous carcinoma may be responsible for lower strain ratio but false negative strain ratio in infiltrative ductal carcinoma could be due early stage of malignancy. Hui Zhi et al ${ }^{(19)}$ also found false negative finding on elastography in early stages of invasive ductal carcinoma. When using strain elastography, one should pay attention to all the factors that would affect the stiffness of the lesions and causing misleading results because, not all hard lesions are malignant and vice-versa.

With strain ratio cut-off limit of 3 we obtained sensitivity of $89.47 \%$, specificity of $85.48 \%$, PPV of $79.07 \%$ and NPV of $92.98 \%$ similar to the reports published previously ${ }^{(16,17,18)}$. It is important to note that the strain ratio is dependent on the manufacturer of the elastography machine. According to Redling $\mathrm{K}^{(20)}$ combination of BIRADS, Tsukuba elasticity score and strain ratio gives sensitivity of $95 \%$ and a specificity of $85 \%$. In the present study combined use of gray scale ultrasonography and strain elastography using strain ratio sensitivity of $97.37 \%$ specificity of $96.77 \%$, PPV of $94.87 \%$ and NPV $98.36 \%$ was achieved. Our result showed higher specificity than Redling $\mathrm{K}^{(20)}$ the reason could be higher cutoff limit of strain ratio that is 3 instead of 2.5. Subjective bias resulting from use of visual elastography score in the assessment of elastography images was avoided.

There are few limitations to the present study. Firstly, elastographic image is always superimposed on the gray scale image; consequently, a bias is introduced. Secondly, Acquisition and analysis of elastographic images is operator dependent. Inter and intra-observer variability is another factor which needs to be considered hence studies with larger numbers of lesions and multiple observers are needed to solve the problem.

\section{Conclusion}

In conclusion, strain elastography using strain ratio is less sensitive but more specific as compared to gray scale ultrasonography and when these two modalities used in combination the number of false results can be reduced which will increase the overall yield of the examination with subsequent reduction in unnecessary biopsies. Combination of two or more imaging methods increases the diagnostic confidence which can always help to develop cost-effective strategies for practices around the world

Source(s) of support: Nil

Conflicting Interest: Nil 


\section{References}

1. Dumitrescu R, Cotarla I. Understanding breast cancer risk-where do we stand in 2005? J cellular and molecular medicine 2005; 9:208-221

2. Yi A, Cho N, Chang JM, Koo HR, La Yun B, Moon WK. Sonoelastography for 1,786 nonpalpable breast masses: diagnostic value in the decision to biopsy. Eur Radiol 2012; 22:1033-1040

3. Schaefer FK, Heer I, Schaefer PJ, Mundhenke C, Osterholz S, Order BM, et al. Breast ultrasound elastography: results of 193 breast lesions in a prospective study with histopathologic correlation. Eur J Radiol 2011; 77:450-456

4. Scaperrotta G, Ferranti C, Costa C, Mariani L, Marchesini M, Suman L, et al. Role of sonoelastography in non-palpable breast lesions. Eur Radiol 2008; 18:23812389

5. American College of Radiology. Breast imaging reporting and data system ultrasound. In: American College of Radiology,ed. Breast imaging reporting and data system, 4th ed. Reston,VA: American College of Radiology, 2003

6. Chao TC, Lo YF, Chen SC, Chen MF. Prospective sonographic study of 3093 breast tumors. J Ultrasound Med 1999; 18:363-370

7. Zhi H, Ou B, Luo B.M, Feng X, Wen Y.L, Yang H.Y. Comparison of ultrasound elastography, mammography, and sonography in the diagnosis of solid breast lesions. J Ultrasound Med 2007; 26:807815

8. McNicholas MM, Mercer PM, Miller JC, McDermott EW, O'Higgins NJ, MacErlean DP. Color Doppler sonography in the evaluation of palpable breast masses. AJR Am J Roentgenol 1993; 161:765-771

9. Choi HY, Kim HY, Baek SY, Kang BC, Lee SW. Significance of resistive index in color Doppler ultrasonogram: differentiation between benign and malignant breast masses. Clin Imaging 1999; 23:284-288

10. Stavros AT, Thickman D, Rapp CL, Dennis MA, Parker SH, Sisney GA. Solid breast nodules: use of sonography to distinguish between benign and malignant lesions. Radiology 1995; 196:123-134

11. Hong AS, Rosen EL, Soo MS, Baker JA. BI-RADS for Sonography: Positive and negative predictive values of sonographic features. AJR 2005; 184:1260-1265

12. Melania C, Paolo B, Roberta L, Gianluca F, Antonino M, Lorenzo B. Characterization of solid breast masses and use of the sonographic Breast Imaging Reporting and Data System Lexicon. J Ultrasound Med 2006; 25:649-659

13. Mary SS, Jay AB,d Eric LR . Sonographic Detection and Sonographically Guided Biopsy of Breast Microcalcifications' Breast Imaging. AJR 2003;180: 941-948

14. Tardivon A, El Khoury C, Thibault F, Wyler A, Barreau B, Neuenschwander S. Elastography of the breast: a prospective study of 122 lesions. J Radiol ;2007; 88: 657-662

15. Cho N, Moon WK, Kim HY, Chang JM, Park SH, Lyou CY. Sonoelastographic strain index for differentiation of benign and malignant nonpalpable breast masses. J Ultrasound Med. 2010; 29:1-7

16. Zhao QL, Ruan LT, Zhang H, Yin YM, Duan SX. Diagnosis of solid breast lesions by elastography 5-point score and strain ratio method. Eur J Radiol. 2012; 81:32453249

17. Gheonea IA, Stoica Z, Bondari S. Differential diagnosis of breast lesions using ultrasound elastography. Indian $\mathbf{J}$ Radiol Imaging 2011; 21:301-305

18. Hiltawsky KM, Kruger M, Starke C, Heuser L, Ermert H, Jensen A. Freehand ultrasound elastography of breast lesions: 
clinical results. Ultrasound Med Biol 2001; 27: 1461-1469

19. Hui Zhi, Bing Ou, Bao-Ming Luo, Xia Feng, Yan-Ling Wen, Hai-Yun Yang, Comparison of Ultrasound Elastography, Mammography, and Sonography in the Diagnosis of Solid Breast Lesions. J Ultrasound Med 2007; 26:807-815

20. Redling K, Schwab F, Siebert M, Schötzau A, Zanetti-Dällenbach R. Elastography Complements Ultrasound as Principle Modality in Breast Lesion Assessment. Gynecol Obstet Invest 2017; 82:119-124 